\title{
UC Cooperative Extension explores a farm-to-WIC program
}

\author{
by Lucia L. Kaiser, Cathi Lamp, Chutima \\ Ganthavorn, Lucrecia Farfan-Ramirez, \\ Tammy McMurdo, Marita Cantwell and \\ Shermain Hardesty
}

To increase fruit and vegetable consumption, the federal Special Supplemental Nutrition Program for Women, Infants and Children (WIC) distributes cash vouchers to low-income women with children to buy fruits and vegetables. The program reaches almost half of the infants and one-quarter of children under 5 years old in the United States. UC Cooperative Extension (UCCE) conducted a survey of produce preferences and buying habits among WIC participants in Tulare, Alameda and Riverside counties in 2010 to guide the development of a farm-to-WIC program that would connect small local growers to the WIC market. Based on the results, the UCCE team developed a list of 19 produce items to promote in a possible new farm-to-WIC program.

A s interest in sustainable food systems has increased, farm-to-school and farm-to-institution partnerships have evolved to bring locally grown food to nearby communities. Changes in the federal Special Supplemental Nutrition Program for Women, Infants and Children (WIC) are now opening the door for new partnerships between local growers and WIC food outlets. Monthly cash-value vouchers allow participants to choose a wide variety of fruits and vegetables. To inform the possible development of a farm-to-WIC program by UC Cooperative Extension (UCCE), we surveyed WIC participants on their produce preferences and buying habits.

WIC provides supplemental foods to low-income pregnant, breastfeeding, nonbreastfeeding postpartum women, and infants and children up to 5 years old who are at nutritional risk; the program also provides nutrition education and

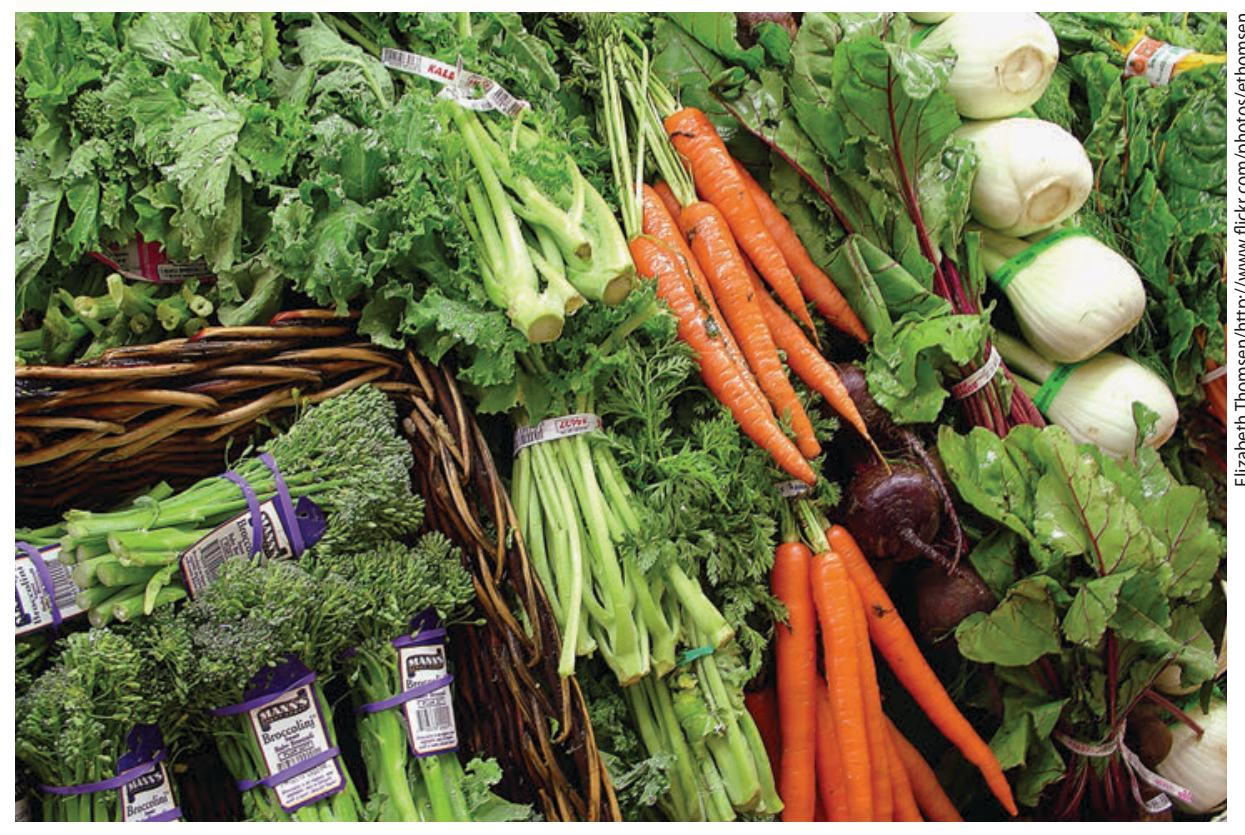

Participants in the Special Supplemental Nutrition Program for Women, Infants and Children (WIC) can now purchase fresh produce monthly at participating farmers markets or WIC stores.

referrals to social and health services. In California, which has the nation's largest WIC program, 82 local agencies serve about 1.43 million participants at 623 local centers. WIC participants redeem vouchers each month at 4,000 grocery stores statewide. About $40 \%$ shop at WIC-only stores, which stock and sell only WICauthorized foods.

All authorized vendors, including the WIC-only stores, are required to stock all WIC foods (see box, page 17). Before 2009, the only produce item in WIC food packages - the particular foods and amounts that may be purchased with the vouchers each month - was fresh carrots. Now, under the new federal guidelines, all stores participating in WIC (both regular grocery and WIC-only stores) must provide a minimum number of fruits and vegetables.

\section{Healthy fruits and vegetables}

The U.S. Dietary Guidelines published in 2010 continue to emphasize the importance of consuming more fruits and vegetables to optimize health (USDHHS/ USDA 2011). A diet rich in fruits and vegetables has been associated with reduced risks of chronic illnesses such as heart disease, stroke and cancer (Liu 2003). A national longitudinal cohort study that followed participants for 19 years found an association between higher intakes of fruits and vegetables and lower incidence of and mortality from cardiovascular disease (Bazzano et al. 2002). In a recent systematic review, greater intake of green leafy vegetables was associated with the reduced risk of type 2 diabetes (Carter et al. 2010).

Fruits and vegetables are rich in vitamins and minerals, as well as other phytochemicals that may protect against diseases. They also provide potassium and dietary fiber and tend to be less energy dense (lower in calories) than foods with added sugars and solid fats. National studies have found associations between low fruit and vegetable consumption and greater abdominal fat in adolescent boys (Bradlee et al. 2009) and obesity in adults (Ledikwe et al. 2006). Increasing the consumption of fruits and vegetables can be an effective strategy for weight management in combination with other strategies such as caloric restriction and physical activity (Ledoux et al. 2011).

Online: http://californiaagriculture.ucanr.org/ landingpage.cfm?article=ca.v066n01p15\&fulltext=yes DOI: 10.3733/ca.v066n01p15 


\section{Reaching almost half of infants and one-quarter of U.S. children under 5 years old, the WIC program provides an unparalleled opportunity to increase fruit and vegetable consumption.}

\section{Low consumption nationally}

California is a major producer of fruits and vegetables in the United States, but these foods are underconsumed in California and other states (Backman et al. 2007). In 2009, only $40 \%$ of California adults consumed fruit two or more times per day, and only $27 \%$ consumed vegetables three or more times per day (CDC 2010). In a national sample, only $50 \%$ of 2- to 5-year-olds surveyed from 1999 to 2002 met the MyPyramid fruit intake recommendation and only $22 \%$ met the vegetable intake recommendation; in older age groups, these percentages were even lower (Lorson et al. 2009).

Low-income households, in particular, face barriers to consuming more fruits and vegetables (Dubowitz et al. 2008; Morland and Filomena 2007; Yeh et al. 2008). UCCE research among low-income Latino families in California found that food insecurity - defined as the lack of access of all people at all times to enough food for an active, healthy life - is associated with lower household supplies and consumption of fruits and vegetables (Kaiser et al. 2003, 2004). In addition to household financial constraints, the limited availability of fruits and vegetables in low-income neighborhoods also appears to account for some of the disparities in intake across ethnic groups and socioeconomic levels (Morland and Filomena 2007). Domestic food assistance programs can provide financial incentives for people to buy more fruits and vegetables,

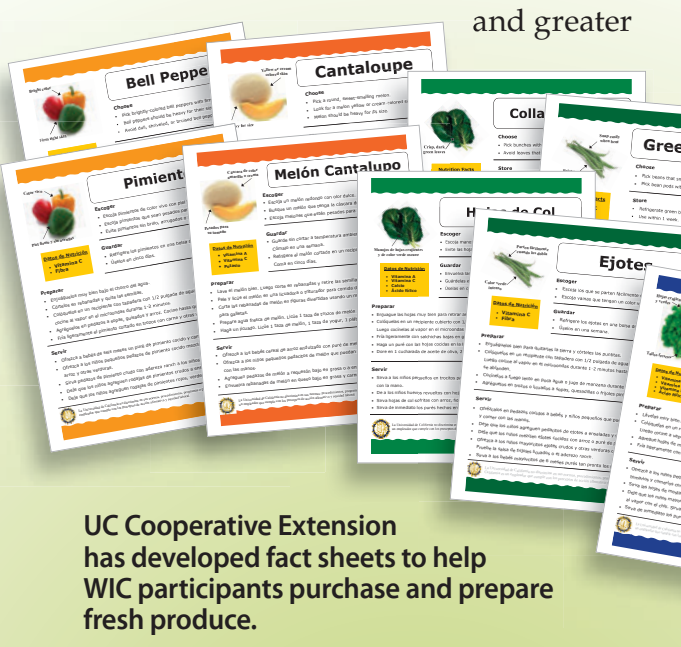

demand could ultimately improve local availability. However, small stores in lowincome urban and rural neighborhoods find it challenging to supply a variety of high-quality produce at affordable prices.

In 2009, more than 9.1 million lowincome women, infants and children received WIC nutrition education and supplementary foods and services, at a cost of $\$ 6.5$ billion (USDA 2011). Reaching almost half of infants and one-quarter of U.S. children under 5 years old, the WIC program provides an unparalleled opportunity to increase fruit and vegetable consumption (Oliveira and Frazao 2009).

\section{Fresh produce in WIC programs}

Historically, the only produce item allowed by federal regulations in the standard WIC food package was fresh carrots, and this food was only available to women who were exclusively breastfeeding their infants (not receiving WIC formula). In 1992, a limited Farmers' Market Nutrition Program began providing vouchers worth about $\$ 10$ to $\$ 30$ per year to each WIC recipient to purchase fresh, locally grown fruits and vegetables. In 2007, only about 2.3 million WIC participants received this benefit.

In a demonstration project conducted in 2001, the Public Health Foundation in Los Angeles examined the impact of expanding this WIC benefit by providing \$40 per month to postpartum WIC participants for the purchase of fruits and vegetables in either the usual WICauthorized grocery stores or farmers markets (Herman et al. 2008). Compared to a control group, who received diapers, the intervention group increased their intake of fruits and vegetables and sustained higher consumption levels 6 months after the subsidy ended. Regardless of whether women were allowed to use their vouchers at a supermarket or farmers market, the redemption rate - which reflects the extent to which participants exchanged the vouchers for food - was about $90 \%$. Moreover, participants purchased a wide variety of both fruits and vegetables (Herman et al. 2006).

In 2006, the U.S. Institute of Medicine published recommendations to change the WIC food packages, calling for the distribution of a wide variety of fruits and vegetables (IOM 2005). In October 2009, California WIC implemented a major overhaul of the state's WIC food packages and began distributing cash vouchers worth $\$ 6$ to $\$ 10$ per month per recipient (ages 12 months and older) for fruits and vegetables, to be redeemed at any authorized vendor.

\section{New WIC strategies}

The U.S. Department of Agriculture's Economic Research Service estimates that the revised WIC food packages will generate $\$ 4.6$ billion nationwide in annual food retail sales after rebates (Hanson and Oliveira 2009). Of that amount, about $\$ 1.3$ billion in farm revenues may be linked to WIC foods. (WIC also provides milk, cheese, eggs, beans, cereals and juice.) However, since WIC participants may in part be using vouchers to pay for food they had previously bought with their own funds, a conservative estimate is that the monthly WIC vouchers increase food expenditures by $26 \%$, translating into a net addition to farm revenues of \$331 million nationwide.

Achieving both the health and economic benefits of this policy change - the expanded distribution of fruits and vegetables to WIC participants - may require new strategies to improve WIC participants' access to and use of fruits and vegetables. These strategies must consider the special needs of low-income participants with limited access to transportation and of stores with small profit margins within their communities.

Furthermore, the WIC population is ethnically diverse. In California, the majority of participants (78\%) are Latino, then white (8\%), black (5.5\%), Asian (5\%) and Native American (0.9\%) (California WIC Branch, unpublished data, 2008). 
WIC serves a vulnerable group, including pregnant and nursing mothers, and young children who are developing preferences for new foods.

Our working hypothesis was that a farm-to-WIC program, coupled with education on produce stocking for vendors and point-of-purchase information for WIC clients, could help increase the local availability of culturally preferred foods, the redemption of vouchers and, ultimately, the consumption of fresh fruits and vegetables.

\section{UCCE explores farm-to-WIC program}

In spring 2010, UCCE conducted a survey among WIC participants in Tulare, Alameda and Riverside counties to guide the development of a farm-to-WIC program that would connect small local growers to the WIC market through local grocery stores and farmers markets. We wanted to determine interest among WIC clients in purchasing locally produced foods and the factors influencing their shopping decisions. The Institutional
Review Board at UC Davis approved the study protocol under exempt status.

We pilot-tested the wording and format with 20 English- and Spanishspeaking WIC participants in Yolo County and modified the survey accordingly. The final version contained 21 questions related to WIC shopping practices and educational needs, including client satisfaction with the quality and variety of produce in WIC stores, produce items purchased with WIC vouchers, factors underlying produce choices and information needed to make better use of the vouchers.

In each county, a UCCE staff member and supervisor attended a Web-based training on administering the survey. Then, UCCE staff members interviewed participants in WIC clinics in the three counties while they waited for their mandatory appointments. Criteria for inclusion in the survey were (1) ability to speak English or Spanish well enough to respond to questions, (2) receipt of WIC cash-value vouchers for fruits and vegetables since the rollout in October 2009 and (3) purchaser of most of WIC foods in their household. Our intent was to interview 300 WIC participants (100 from each county) between April and May 2010. Each interview lasted about 10 minutes. Of the 300 WIC clients approached, only 12 did not complete the survey, mainly because they were called for their WIC appointments and did not return to the waiting area.

Two UCCE staff members entered the data in an Excel spreadsheet, which was uploaded and analyzed in SAS version 9.2 (Cary, NC). Basic descriptive statistics included means and frequencies. Chisquare and Wilcoxon rank sum tests were used to examine differences in demographic variables and shopping practices among the three sites.

\section{Shopping practices}

Educational level, language preference and ethnicity differed among the three sites (table 1). The participants reported using their WIC fruit and vegetable

\section{WIC foods}

WIC food packages include infant jarred fruit and vegetables; milk (mostly lower-fat cow's milk), soy milk and tofu; cheese; eggs; whole grains, including whole wheat bread, brown rice and oatmeal; cold or hot breakfast cereal; peanut butter; beans, peas or lentils (dry or canned); juice, $100 \%$ as concentrate or bottled; and fresh, frozen or canned fruits and vegetables.

Although states can limit WIC foods, the California WIC program allows a wide variety of fruits and vegetables. Some specific produce items are not allowed, including any potatoes other than yams or sweet

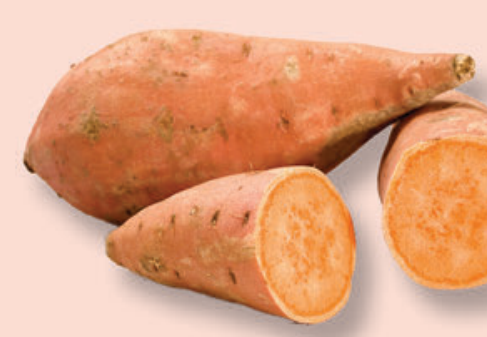
potatoes, left; any food or product from a salad bar or deli; party trays; fruit baskets; decorative vegetables and fruits, such as chilies or garlic on a string or painted pumpkins; nuts or

fruit-nut mixtures; edible blossoms, such as squash blossoms; bagged salad, vegetable or fruit kits; and dried fruits and vegetables.

California allowable and unallowable WIC foods are listed at:

www.cdph.ca.gov/programs/wicworks/WIC\%20Foods/ WICAuthorizedFoodListShoppingGuide-4-2010.pdf.

\begin{tabular}{|c|c|c|c|}
\hline & $\begin{array}{c}\text { Alameda } \\
(n=88)\end{array}$ & $\begin{array}{l}\text { Riverside } \\
(n=101)\end{array}$ & $\begin{array}{c}\text { Tulare } \\
(n=100)\end{array}$ \\
\hline Age $(\text { mean } \pm S D)^{*}$ & $28.1 \pm 6.9$ & $27.6 \pm 7.1$ & $28.2 \pm 8.0$ \\
\hline \multicolumn{4}{|l|}{ Education (\%)† } \\
\hline $0-2$ years & 1.1 & 0.0 & 3.0 \\
\hline 3-6 years & 7.8 & 7.9 & 18.8 \\
\hline $7-11$ years & 38.9 & 27.7 & 25.7 \\
\hline High school/GED & 38.9 & 46.5 & 40.6 \\
\hline College & 13.3 & 17.8 & 11.9 \\
\hline \multicolumn{4}{|l|}{ Language (\%)‡ } \\
\hline English only & 40.2 & 18.8 & 26.5 \\
\hline Spanish only & 32.0 & 30.7 & 36.3 \\
\hline English/Spanish & 26.8 & 50.5 & 33.3 \\
\hline English and other (Hmong) & 1.0 & 0.0 & 2.0 \\
\hline Spanish/other (Mixtec) & 0.0 & 0.0 & 1.0 \\
\hline \multicolumn{4}{|l|}{ Ethnicity (\%)§ } \\
\hline White & 1.1 & 7.9 & 9.0 \\
\hline Latino & 64.0 & 90.1 & 86.0 \\
\hline Black & 25.8 & 1.0 & 1.0 \\
\hline Asian & 4.5 & 0.0 & 1.0 \\
\hline Native American & 0.0 & 0.0 & 1.0 \\
\hline Other & 1.1 & 1.0 & 2.0 \\
\hline Black and Native American & 1.1 & 0.0 & 0.0 \\
\hline Latino and Black & 2.3 & 0.0 & 0.0 \\
\hline $\begin{array}{l}{ }^{*} \text { Means + standard deviation (SD) no } \\
+P<0.06 \text {, using chi-square analyses. } \\
\neq P<0.01 \text {, using chi-square analyses. } \\
\S P<0.0001 \text {, using chi-square analyse }\end{array}$ & g Wilcoxon ran & sum. & \\
\hline
\end{tabular}


vouchers at a variety of stores (table 2). More of the Alameda $(76.3 \%)$ and Tulare $(45 \%)$ county participants reported using the WIC-only stores (either alone or along with a supermarket) than did the Riverside County participants (15.8\%).

Stocking produce is relatively new to WIC-only stores; before rollout of the new WIC food packages in October 2009, these stores were only required to stock limited amounts of fresh carrots. Whereas most WIC participants (58.0\% to $72.3 \%$ ) responded that their preferred stores offered many choices, fewer participants ( $18.5 \%$ to $41.0 \%$ ) rated the produce quality as "excellent." Key factors determining purchase decisions were produce quality and freshness, and nutrient value (vitamins and minerals). Cost seemed relatively less important, possibly because WIC participants were procuring produce with the vouchers.

\begin{tabular}{|c|c|c|c|}
\hline \multirow{3}{*}{ Survey question } & $\begin{array}{l}\text { tore, satisfa } \\
\text { tors, } 2010\end{array}$ & ction level a & \\
\hline & $\begin{array}{l}\text { Alameda } \\
(n=88)\end{array}$ & $\begin{array}{l}\text { Riverside } \\
(n=101)\end{array}$ & $\begin{array}{c}\text { Tulare } \\
(n=100)\end{array}$ \\
\hline & \multicolumn{3}{|c|}{$\ldots \ldots \ldots \ldots \ldots \% \ldots \ldots \ldots$} \\
\hline \multicolumn{4}{|l|}{$\begin{array}{l}\text { Where do you shop for fruits and } \\
\text { vegetables with your WIC vouchers?* }\end{array}$} \\
\hline Supermarket & 21.7 & $83.2+$ & 40.0 \\
\hline WIC-only store & 45.4 & 8.9 & 31.0 \\
\hline Supermarket and WIC-only store & 30.9 & 6.9 & 14.0 \\
\hline Small grocery store & 0.0 & 0.0 & 4.9 \\
\hline All other and combination & 2.1 & 1.0 & 10.8 \\
\hline \multicolumn{4}{|l|}{$\begin{array}{l}\text { What is the quality of the fruits and } \\
\text { vegetables sold at the store where you } \\
\text { prefer to use your WIC vouchers?‡ }\end{array}$} \\
\hline Unacceptable & 0.0 & 0.0 & 0.0 \\
\hline Poor & 1.1 & 1.0 & 0.0 \\
\hline Fair & 9.2 & 11.0 & 4.0 \\
\hline Good & 71.1 & 59.0 & 55.0 \\
\hline Excellent & 18.5 & 29.0 & 41.0 \\
\hline \multicolumn{4}{|l|}{$\begin{array}{l}\text { What is the variety of fruits and vegetables } \\
\text { sold at the store where you prefer to use } \\
\text { your WIC vouchers?§ }\end{array}$} \\
\hline No choices & 0.0 & 0.0 & 0.0 \\
\hline Very few choices & 0.0 & 2.0 & 1.0 \\
\hline Few choices & 8.0 & 6.9 & 10.8 \\
\hline Some choices & 29.4 & 18.8 & 30.9 \\
\hline Many choices & 60.8 & 72.3 & 58.0 \\
\hline \multicolumn{4}{|l|}{$\begin{array}{l}\text { How important are the following reasons } \\
\text { when choosing which fresh fruits } \\
\text { and vegetables to buy (data for "very } \\
\text { important" responses shown): }\end{array}$} \\
\hline I like the taste (NS) & 88.5 & 92.1 & 88.2 \\
\hline My family likes the taste $(P<0.02)$ & 84.5 & 98.0 & 85.3 \\
\hline They are on sale $(P<0.004)$ & 67.0 & 73.3 & 52.0 \\
\hline They are available where I shop $(P<0.002)$ & 83.5 & 95.1 & 75.5 \\
\hline They are fresh and good quality (NS) & 93.8 & 99.0 & 96.1 \\
\hline I need them for a recipe or meal (NS) & 50.0 & 63.4 & 58.8 \\
\hline They have lots of vitamins/minerals (NS) & 93.8 & 99.0 & 96.1 \\
\hline $\begin{array}{l}\text { * } P<0.0001 \text {, using chi-square analyses. } \\
+ \text { Red indicates highest responses for each question. } \\
\text { ₹ } P<0.02 \text {, using chi-square analyses. } \\
\S \text { Not significant, using Wilcoxon rank sum. }\end{array}$ & & & \\
\hline
\end{tabular}

Among those not using WIC-only stores $(n=73)$, the main reason for not doing so was inconvenience $(45.5 \%, 41.7 \%$ and $19.2 \%$ in Alameda, Riverside and Tulare counties, respectively [data not shown]). Low quality and lack of variety of produce in the WIC-only stores were also factors $(18.2 \%, 19.4 \%$ and $15.3 \%$ in Alameda, Riverside and Tulare counties, respectively).

Using input from UCCE farm advisors in the three counties regarding which crops could be locally grown and the list

TABLE 3. Self-reported fruit and vegetable purchases of WIC participants, 2010*

\begin{tabular}{|c|c|c|c|c|c|c|}
\hline \multirow[b]{2}{*}{ Item } & \multicolumn{2}{|c|}{ Alameda $(n=88)$} & \multicolumn{2}{|c|}{ Riverside $(n=101)$} & \multicolumn{2}{|c|}{ Tulare $(n=100)$} \\
\hline & Bought & $\begin{array}{l}\text { Would } \\
\text { buy }\end{array}$ & Bought & $\begin{array}{l}\text { Would } \\
\text { buy }\end{array}$ & Bought & $\begin{array}{c}\text { Would } \\
\text { buy }\end{array}$ \\
\hline \multirow{2}{*}{\multicolumn{7}{|c|}{ Fruits }} \\
\hline & & & & & & \\
\hline Blueberries & 8.0 & 42.1 & 12.9 & 18.8 & 7.0 & 38.0 \\
\hline Cactus fruit & 3.4 & 28.4 & 4.0 & 13.9 & 4.0 & 28.0 \\
\hline Cantaloupet & 45.5 & 64.8 & 57.4 & 30.7 & 63.0 & 79.0 \\
\hline Grapes & 83.0 & 70.5 & 55.5 & 41.6 & 41.0 & 71.0 \\
\hline Guava & 6.8 & 48.9 & 6.9 & 16.8 & 9.0 & 53.0 \\
\hline Honeydew melon & 9.1 & 44.3 & 36.6 & 27.7 & 23.0 & 46.0 \\
\hline Strawberries & 77.3 & 62.5 & 76.2 & 42.6 & 73.0 & 81.0 \\
\hline Watermelon & 34.1 & 77.3 & 28.7 & 29.7 & 53.0 & 83.0 \\
\hline \multicolumn{7}{|l|}{ Vegetables } \\
\hline Bell pepper & 22.7 & 51.1 & 26.7 & 17.8 & 33.0 & 51.0 \\
\hline Bok choi & 6.8 & 15.9 & 0.0 & 2.0 & 4.0 & 7.0 \\
\hline Broccoli & 73.9 & 69.3 & 69.3 & 38.6 & 77.0 & 86.0 \\
\hline Cabbage & 26.1 & 58.0 & 29.7 & 16.8 & 48.0 & 56.0 \\
\hline Cabbage (Napa) & 10.2 & 23.9 & 7.9 & 7.9 & 7.0 & 27.0 \\
\hline Carrot & 59.1 & 55.7 & 67.3 & 25.7 & 75.0 & 70.0 \\
\hline Cauliflower & 27.3 & 53.4 & 32.7 & 16.8 & 46.0 & 58.0 \\
\hline Chard & 3.4 & 27.3 & 5.0 & 6.9 & 7.0 & 18.0 \\
\hline Chili pepper & 15.9 & 34.1 & 23.8 & 19.8 & 42.0 & 51.0 \\
\hline Collards & 6.8 & 31.8 & 4.0 & 5.0 & 5.0 & 9.0 \\
\hline Corn & 48.9 & 71.6 & 47.5 & 32.7 & 56.0 & 79.0 \\
\hline Daikon & 2.3 & 11.4 & 1.0 & 4.0 & 3.0 & 5.0 \\
\hline Eggplant & 5.7 & 27.3 & 6.9 & 13.9 & 4.0 & 17.0 \\
\hline Gai lan & 1.1 & 12.5 & 1.0 & 2.0 & 1.0 & 6.0 \\
\hline Green beans & 29.6 & 53.4 & 31.7 & 16.8 & 43.0 & 55.0 \\
\hline Jicama & 11.4 & 40.9 & 25.7 & 16.8 & 31.0 & 59.0 \\
\hline Lettuce & 48.9 & 69.3 & 54.5 & 25.7 & 60.0 & 62.0 \\
\hline Long beans & 5.7 & 18.2 & 1.0 & 4.0 & 9.0 & 23.0 \\
\hline Mustard greens & 11.4 & 31.8 & 2.0 & 3.0 & 3.0 & 13.0 \\
\hline $\begin{array}{l}\text { Nopales (cactus } \\
\text { pads) }\end{array}$ & 9.1 & 31.8 & 9.9 & 18.8 & 25.0 & 44.0 \\
\hline Onion & 54.6 & 60.2 & 49.5 & 26.7 & 61.0 & 74.0 \\
\hline Radish & 8.0 & 42.1 & 12.9 & 12.9 & 34.0 & 56.0 \\
\hline Spinach & 25.0 & 53.4 & 31.7 & 16.8 & 29.0 & 47.0 \\
\hline Summer squash & 20.5 & 37.5 & 22.8 & 17.8 & 44.0 & 51.0 \\
\hline Sweet potato & 40.9 & 50.0 & 26.7 & 20.8 & 32.0 & 47.0 \\
\hline Tomatillo & 20.5 & 42.1 & 26.7 & 13.9 & 45.0 & 53.0 \\
\hline Tomato & 70.5 & 69.3 & 79.2 & 33.7 & 85.0 & 75.0 \\
\hline Winter squash & 3.4 & 19.3 & 8.9 & 8.9 & 8.0 & 23.0 \\
\hline
\end{tabular}


of WIC-allowable foods (see box, page 17), we included survey questions about participants' use of WIC vouchers in the past 6 months to purchase 36 different produce items. The survey asked whether the item had been purchased (bought) and whether they would be interested in buying it in the future (would buy) if it were available in their preferred store. More than 30\% of participants in all locations reported having bought or having a future interest in buying most items, except for bok choi, cactus fruit, chard, daikon, eggplant, gai lan, long beans, Napa cabbage and winter squash (table 3). In addition, the survey allowed participants to write in other commonly purchased items. The most common responses (in rank order) were banana, apple, orange, mango, avocado and pineapple.

In a joint meeting, UCCE farm and nutrition advisors from the three counties reviewed the survey results and generated a shorter list of fresh fruits and vegetables as a starting point for discussions with growers and WIC vendors. Key considerations included (1) crop grown in the local area, (2) demand from WIC participants (greater than $30 \%$ purchased or expressed an interest in purchasing), (3) postharvest handling manageable for growers and stores and (4) appropriate for the WIC population of pregnant women, infants, toddlers and young children, including nutritional benefits and taste acceptability to young children.

Weighing the considerations equally, the UCCE team identified 19 candidate produce items: bell pepper, broccoli, cabbage, cantaloupe, carrot, collards, corn, grapes, green beans, lettuce, mustard greens, nopales (cactus pads), spinach, strawberries, sweet potato, tomatillo, tomato and watermelon (table 3). Although mustard greens and collards were not popular across all sites, the advisors gauged a potential market in Alameda County, so these were retained. Based on write-in responses, oranges were added.

\section{Next steps}

The survey showed that WIC participants were interested in purchasing fresh produce with better quality and more variety. Some WIC participants that we surveyed said they avoided shopping at WIC-only stores in part because these interests were not met. The survey helped to generate a list of 19 produce items to explore in a possible farm-to-WIC program.

The UCCE team met with growers and local WIC vendors to explore these marketing opportunities. The nutrition advisors and staff have developed and pilot-tested fact sheets for a limitedliteracy audience (see page 16). Each one features a single fruit or vegetable, with tips on easy and appealing ways to prepare and serve them to young children. Along with training on safe and careful handling of fresh produce, stores involved in the project (rather than farmers markets) will receive these point-of-purchase materials to stimulate increased sales of fresh produce.

The study and these subsequent activities provide an opportunity for us to further examine the feasibility of a UCCEled farm-to-WIC program. The purpose of such a program would be to increase the consumption of a wide variety of fresh produce, with a focus on locally grown produce when available. They also

\section{References}

Backman D, Sugerman S, Mattingly S. 2007. Fruits and vegetables. In: California Food Guide. California Department of Health Care Services and California Department of Public Health. Sacramento, CA. www.dhcs.ca.gov/ dataandstats/reports/Documents/CaliforniaFoodGuide/2 FruitsandVegetables.pdf (accessed 11/29/10).

Bazzano LA, He J, Ogden LG, et al. 2002. Fruit and vegetable intake and risk of cardiovascular disease in U.S. adults: The first National Health and Nutrition Examination Survey Epidemiologic Follow-up Study. Am J Clin Nutr 76(1):93-9.

Bradlee ML, Singer MR, Qureshi MM, Moore LL. 2009. Food group intake and central obesity among children and adolescents in the Third National Health and Nutrition Examination Survey (NHANES III). Public Health Nutr 13(6):797-805.

Carter P, Gray LJ, Troughton J, et al. 2010. Fruit and vegetable intake and incidence of type 2 diabetes mellitus: Systematic review and meta-analysis. BMJ 341. DOI:10.1136/ bmj.c4229.

[CDC] Centers for Disease Control and Prevention. 2010. State-specific trends in fruit and vegetable consumption among adults — United States, 2000-2009. Morbidity Mortality Weekly Rep 59(35):1125-30.

Dubowitz T, Heron M, Bird C, et al. 2008. Neighborhood socioeconomic status and fruit and vegetable intake among whites, blacks and Mexican Americans in the United States. Am J Clin Nutr 87(6):1883-91.

Hanson K, Oliveira V. 2009. Economic linkages between the WIC program and the farm sector. www.ers.usda.gov/ Publications/EB12/EB12.pdf (accessed 12/20/10).

Herman DR, Harrison GG, Afifi AA, Jenks E. 2008. Effect of a targeted subsidy on intake of fruits and vegetables among low-income women in the Special Supplemental Nutrition Program for Women, Infants and Children. Am J Public Health 98(1):98-105.

Herman DR, Harrison GG, Jenks E. 2006. Choices made by low-income women provided with an economic supple ment for fresh fruit and vegetable purchase. J Am Diet Assoc 106(5):740-4. provide insights into UC's role in benefiting farmers and improving access of lowincome communities to a wide variety of healthy, fresh produce.

L.L. Kaiser is Cooperative Extension Specialist, Department of Nutrition, UC Davis; C. Lamp is Nutrition, Family and Consumer Sciences (NFCS) Advisor, UC Cooperative Extension (UCCE), Tulare County; C. Ganthavorn is NFCS Advisor, UCCE Riverside County; L. Farfan-Ramirez is County Director, UCCE Alameda County; T. McMurdo is Program Representative, California Expanded Food and Nutrition Education Program, Davis; M. Cantwell is Cooperative Extension Specialist, Department of Plant Sciences, UC Davis; and S. Hardesty is Cooperative Extension Specialist, Department of Agricultural and Resource Economics, UC Davis.

We acknowledge the California Department of Food and Agriculture for funding this project. We also gratefully acknowledge Penny Leff, Manuel Jimenez, Aziz Baameur, Jose Aguiar and the WIC agency staff in Alameda, Tulare and Riverside counties for their assistance.

[IOM] Institute of Medicine. 2005. WIC Food Packages: Time for a Change. Committee to Revise the WIC Food Packages. Washington, DC: Nat Acad Pr. 415 p.

Kaiser LL, Martin A, Metz DL, et al. 2004. Food insecurity prominent among low-income California Latinos. Cal Ag 58:18-23

Kaiser LL, Melgar-Quinonez H, Townsend MS, et al. 2003. Food insecurity and food supplies in Latino households with young children. J Nutr Educ Behav 35(3):148-53.

Ledikwe JH, Blanck HM, Kettel Khan L, et al. 2006. Dietary energy density is associated with energy intake and weight status in U.S. adults. Am J Clin Nutr 83(6):1362-8. Ledoux TA, Hingle MD, Baranowski T. 2011. Relationship of fruit and vegetable intake with adiposity: A systematic review. Obesity Rev 12(5):e143-50. DOI 10.1111/j.1467789X.2010.00786.x.

Liu RH. 2003. Health benefits of fruit and vegetables are from additive and synergistic combinations of phytochemicals. Am J Clin Nutr 78(suppl):517-20S.

Lorson BA, Melgar-Quinonez HR, Taylor CA. 2009. Cor relates of fruit and vegetable intakes in U.S. children. J Am Diet Assoc 109(3):474-8.

Morland K, Filomena S. 2007. Disparities in the availability of fruits and vegetables between racially segregated urban neighbourhoods. Public Health Nutr 10(12):1481-9. Oliveira V, Frazao E. 2009. The WIC Program: Background, trends and economic issues. US Department of Agriculture. Washington, DC. www.ers.usda.gov/Publications/ ERR73 (accessed 12/20/10)

[USDA] US Department of Agriculture. The WIC program. Economic Research Service. Washington, DC. www.ers. usda.gov/Briefing/WIC (accessed 10/21/11)

[USDHHS/USDA] US Department of Health and Human Services, USDA. 2011. Dietary Guidelines for Americans 2010. www.dietaryguidelines.gov (accessed 1/31/11).

Yeh MC, Ickes SB, Lowenstein LM, et al. 2008. Understanding barriers and facilitators of fruit and vegetable consumption among a diverse multi-ethnic population in the USA. Health Promot Int 23(1):42-51. 